II $(64,52 \%$ và 70,97\%).

- Khoảng cách động mạch xuyênI động mạch đùi sâu đến ụ ngôi, mấu chuyển lớn rất phù hợp trong việc tạo vạt da động mạch xuyênđộng mạch đùi sâu che phủ khuyết hổng.

\section{TÀI LIÊU THAM KHẢO}

1. Pontén B. The fasciocutaneous flap: its use in soft tissue defects of the lower leg. Br J Plast Surg. $1981 ; 34: 215-202$.

2. Algan S., el at. (2020). Profunda femoris artery perforator flaps: a detailed anatomical study.
Journal of Plastic Surgery and Hand Surgery. 1-5.

3. Song Y.G., Chen G.Z., Song Y.L. (1984). The free thigh flap: a new free flap concept based on the septocutaneous artery. Br J Plast Surg., 37:149-159.

4. Shimizu T., Fisher DR., Carmichael SW., et al. (1997). An anatomic comparison of septocutaneous free flaps from the thigh region. Ann Plast Surg. 38:604-610.

5. Reza Ahmadzadeh, B.Sc, Leonard Bergeron, M.D. The Posterior Thigh Perforator Flap or Profunda Femoris Artery Perforator Flap. page 196 - 197. Copyright American Society of Plastic Surgeons.

\title{
CƯỜNG GIÁP DO VIÊM TUYẾN GIÁP HASHIMOTO Ở TRẺ EM
}

\section{TÓM TẮT}

Viêm tuyến giáp Hashimoto (HT) là bệnh lý tuyến giáp mắc phải gây bướu cổ phổ biến ở trẻ em. Đăc trưng lâm sàng của bênh là tình trang suy giáp tiến triển dần dần. Tuy nhiền, bệnh có thể biểu hiện triệu chứng cường giáp trong một giai đoạn thoáng qua (Hashitoxicosis). Mục tiều: Mô tả đặc điểm lâm sàng, xét nghiêm và điều tri của bênh nhân cường giáp do HT. Đối tượng: 39 bệnh nhân cường giáp do HT được chẩn đoán và điều trị tai khoa Nội tiết - Chuyển hóa - Di truyền, Bệnh viện Nhi Trung ương từ 01/2018 đến 12/2019. Phương pháp: Nghiên cứu một loạt ca bệnh bao gôm mô tả đặc điểm lâm sàng, xét nghiêm chức năng tuyến giáp xét nghiêm miễn dịch và điều trị. Kết quả: 39 bệnh nhân được chẩn đoán cường giáp do HT, tuổi trung bình là $9,75 \pm 2,22$ tuổi. Lý do khám bệnh hay gặp nhất là bướu cổ. Tất cả các bệnh nhân được điêu trị Thiamazole; 26 bênh nhân được điều trị Propranolol. Kết luân: Bướu cổ là triệu chứng hay gặp nhất, tỉ lệ mắc bệnh ở nữ nhiều hơn nam. Xác đinh nguyên nhân cường giáp là quan trong. Kháng thể kháng giáp là xét nghiệm quan trọng giúp phát hieên, theo dõi, tiên lượng bệnh.

Tư khóa: Viêm tuyến giáp Hashimoto trẻ em, cường giáp, viêm tuyến giáp tự miễn.

\section{SUMMARY}

HYPERTHYROIDISM CAUSED BY HASHIMOTO'S THYROIDITIS IN CHILDREN

Hashimoto's thyroiditis is one of the most common acquired thyroid disorders with goiter in children. It is characterized clinically by gradual hypothyroidism, however, hyperthyroidism sometimes can be one of clinical manifestations in early course of disease (Hashitoxicosis). Aims: to describe clinical characteristics, biochemical tests and treatment in 39

*Bênh viên Nhi Trung Ương

Chịu trách nhiệm chính: Vũ Chí Dũng

Email: dungvu@nch.org.vn

Ngày nhân bài: 28.12.2020

Ngày phản biên khoa hoc: 15.2.2021

Ngày duyệt bài: 25.2.2021

\section{Nguyễn Trọng Thành*, Vũ Chí Dũng*}

patients diagnosed with Hashitoxicosis. Subjectives: Patients diagnosed with Hashitoxicosis treated in Endocrinology - Metabolism - Genetic Department at the Vietnam National Children's Hospital from January 2018 to December 2019. Methods: case series study. Results: there were totally 39 patients diagnosed with Hashitoxicosis. Their mean age was $9.75 \pm 2.22$ years. Common complaints were goiter. All patients were treated with Thiamazole (Thyrozol) and 26 out of 39 patients received Propranolol. Conclusions: Goiter was the most common complaint. Morbidity rate was higher in girls than boys. It is essential to identify the cause in approaching to a patient who presents signs and symptoms of hyperthyroidism.

Keywords: Hashimoto's thyroiditis in children, hyperthyroidism, autoimmune thyroiditis.

\section{I. ĐĂT VẤN ĐỀ}

Viêm tuyến giáp Hashimoto là bệnh lý tuyến giáp tự miến phổ biến nhất ở trẻ em, còn gọi là viêm tuyến giáp lympho man tính. Trong phần lớn các trường hợp nếu không được điều trị, bệnh sẽ tiến triển dần dần và cuối cùng dẫn đến suy giáp. Tuy nhiên, bệnh có thể biểu hiện ở trạng thái bình giáp, thậm chí cường giáp ở một giai đoạn nhất định trong quá trình tiến triển của bệnh [1]. Tình trạng cường giáp được coi là giai đoạn đầu của viêm tuyến giáp Hashimoto Hashitoxicosis. Chẩn đoán xác định dựa vào sự xuất hiện của kháng thể kháng tuyến giáp trong máu (chủ yếu là thyroperoxidase và thyroglobulin), kèm theo siêu âm tuyến giáp cho thấy hình ảnh nhu mô giảm âm ở những bệnh nhân có biểu hiện lâm sàng [2]. Trên lâm sàng, các trường hợp cường giáp do HT có thể bị bỏ qua do các triệu chứng tiến triển từ từ và không đăc hiêu, trong đó bướu cổ là triệu chứng phổ biến nhất. Tuy nhiên, đôi khi các triệu chứng của bệnh có thể rất điển hình và đòi hỏi cần được can thiệp sớm. Viêm tuyến giáp do HT có thể 
ảnh hưởng đến phát triển thể chất, tâm thần, chất lượng cuộc sống, gây ra các biến chứng cường giáp và tiến triển đến suy giáp nễu không được phát hiện, điêuu trị và theo dõi kịp thời [3]. Vì vậy, chẩn đoán nguyên nhân nhằm tiên lượng quá trình tiến triển sang giai đoạn suy giáp của bệnh nhân là hết sức cần thiết [4].

Xuất phát từ những lý do trên, nghiên cứu được tiến hành nhằm mục tiêu: Mô tả đặc điểm lâm sàng, cận lâm sàng và điều trị ở những bệnh nhân cường giáp do viêm tuyến giáp Hashimoto.

\section{II. ĐỐI TƯỢNG VÀ PHƯƠNG PHÁP NGHIÊN CỨU}

Đối tượng gồm 39 bệnh nhân được chẩn đoán cường giáp do viêm tuyến giáp Hashimoto, được khám và điều trị tại khoa Nội tiết - Chuyển hóa - Di truyền, Bệnh viện Nhi Trung ương từ tháng 01/2018 đến tháng 12/2019.

Nghiên cứu một loạt ca bệnh bao gồm mô tả các đặc điểm về tuổi, giới, cân nặng, triệu chứng lâm sàng (bướu cổ, run tay, gầy sút cân, mắt lồi, mất ngủ, vã vồ hôi, mệt mỏi, hồi hộp đánh trống ngực và những triệu chứng khác nếu có, nhịp tim). Khai thác tiền sử gia đình về bệnh lý tuyến giáp. Đặc điểm xét nghiệm chức năng tuyến giáp (T3, FT4, TSH) và kháng thể kháng tuyến giáp (Anti - Tg; Anti -TPO, TRAb). Đánh giá mật độ và kích thước tuyến giáp bằng phương pháp siêu âmm.

\section{KẾT QUẢ NGHIÊN CỨU}

3.1 Đặc điểm lâm sàng và xét nghiệm. Trong tổng số 39 bệnh nhân, có 34 trẻ nữ (chiếm $87,18 \%$ ) và 5 trẻ nam (chiếm $12,82 \%$ ) với độ tuổi trung bình là $9,75 \pm 2,22$ tuổi, trẻ nhỏ nhất là 3 tuổi và lớn nhất là 13,5 tuổi. Lý do khám bệnh hay gặp nhất là bướu cổ (cổ to tăng dần) chiếm $61,54 \%$ (24/39 bệnh nhân), gầy sút cân (5/39 bệnh nhân, 12,82\%), hồi hộp đánh trống ngực (3 bệnh nhân, 7,69\%) và một số lý do khác. 37/39 bệnh nhân biểu hiện tình trạng bướu cổ. Nhịp tim trung bình của nhóm bệnh nhân nghiên cứu là 117 lần/phút. Tiền sử gia đình: ghi nhận 8 trường hợp gia đình có tiền sử bệnh lý tuyển giáp, trong đó hầu hết là cường giáp và 2 bệnh nhân có bố hoặc mẹ bị ung thư tuyến giáp.

Bảng 3.1. Triệu chứng lâm sàng của bệnh nhân

\begin{tabular}{|c|c|c|}
\hline Triệu chứng & $\mathbf{n}$ & Tỉ lệ (\%) \\
\hline Bướu cố & 37 & 94,87 \\
\hline Run tay & 24 & 61,54 \\
\hline Gầy sút cân & 19 & 48,72 \\
\hline Vã mồ hôi & 15 & 38,46 \\
\hline Mắt lồi & 13 & 33,33 \\
\hline Hồi hộp đánh trống ngực & 13 & 33,33 \\
\hline \multicolumn{3}{|l}{} \\
\hline
\end{tabular}

\begin{tabular}{|c|c|c|}
\hline Mệt mỏi & 8 & 20,51 \\
\hline Mất ngủ & 6 & 16,23 \\
\hline Khác (co giật, cao huyết áp) & 1 & 2,56 \\
\hline
\end{tabular}

Bảng 3.2. Xét nghiệm hóa sinh - miến dịch của bệnh nhân

\begin{tabular}{|c|c|c|}
\hline $\begin{array}{c}\text { Xét } \\
\text { nghiệm }\end{array}$ & $\begin{array}{c}\text { TB } \pm \text { SD/ Trung } \\
\text { vị (khoảng tứ } \\
\text { phân vị) }\end{array}$ & $\begin{array}{c}\text { Trị số } \\
\text { bình } \\
\text { thường }\end{array}$ \\
\hline $\mathrm{T} 3(\mathrm{nmol} / \mathrm{l})$ & $6,71 \pm 2,86$ & $\begin{array}{c}1,9-3,7 \\
\mathrm{nmol} / \mathrm{l}\end{array}$ \\
\hline $\begin{array}{c}\mathrm{FT} 4 \\
(\mathrm{pmol} / \mathrm{l})\end{array}$ & $67,59 \pm 18,87$ & $\begin{array}{c}12-22 \\
\mathrm{pmol} / \mathrm{l}\end{array}$ \\
\hline $\begin{array}{c}\mathrm{TSH} \\
(\mathrm{mIU} / \mathrm{I})\end{array}$ & $0,03 \pm 0,02$ & $\begin{array}{c}0,7-6,4 \\
\mathrm{mIU} / \mathrm{I}\end{array}$ \\
\hline $\begin{array}{c}\mathrm{Anti}-\mathrm{Tg} \\
(\mathrm{U} / \mathrm{ml})\end{array}$ & $\begin{array}{c}1460(989- \\
4000)\end{array}$ & $\begin{array}{c}<115 \\
\mathrm{U} / \mathrm{ml}\end{array}$ \\
\hline $\begin{array}{c}\mathrm{Anti}-\mathrm{TPO} \\
(\mathrm{U} / \mathrm{ml})\end{array}$ & $270(154-484)$ & $\begin{array}{c}0-34 \\
\mathrm{U} / \mathrm{ml}\end{array}$ \\
\hline $\begin{array}{c}\mathrm{TRAb} \\
(\mathrm{IU} / \mathrm{L})\end{array}$ & $8,21(2,58-17)$ & $\begin{array}{c}<1,22 \\
\mathrm{IU} / \mathrm{L}\end{array}$ \\
\hline
\end{tabular}

3.2 Điều trị và kết quả: Tất cả các bệnh nhân đều được điều trị bằng thuốc kháng giáp trạng Thiamazole (Thyrozol) với liêu trung bình $0,59 \pm 0,16 \mathrm{mg} / \mathrm{kg} / \mathrm{ngày}$ và 26 bệnh nhân $(66,67 \%)$ được điêu trị kêtt hợp bằng propranolol với liều $0,98 \pm 0,23 \mathrm{mg} / \mathrm{kg} / \mathrm{ngày}$ để làm giảm nhịp tim và 6 bệnh nhân mất ngủ cần được chỉ định Diazepam (Seduxen) đường uống. Tình trạng lâm sàng của tất cả các bệnh nhân ổn định, các triệu chứng toàn thân và cở năng của cường giáp giảm dân và hết. Các bệnh nhân tiếp tục được hẹn tái khám và theo dõi các triệu chứng lâm sàng kết hợp xét nghiệm hóa sinh miễn dịch.

\section{BÀN LUẦN}

Hashitoxicosis là thuật ngũ̃ dùng để chỉ tình trạng viêm tuyến giáp tự miển ở giai đoạn cường giáp. Tỉ lệ cường giáp trong viêm tuyến giáp Hashimoto dao động từ 6,5\%-11\% tùy theo nghiên cứu [5]. Trong nhóm nghiên cứu của chúng tôi, 39 bệnh nhân cường giáp do viêm tuyến giáp Hashimoto đa số là trẻ nữ với 34 bệnh nhân (chiếm 87,18\%) so với 4 trẻ nam (tỉ lệ $7: 1$ ). Kết quả này tương đồng với một số kết quả nghiên cứu khác trên trên thế giới, tỉ lệ nữ mắc bệnh $\mathrm{HT}$ nhiều hơn nam, tỉ lệ mắc bệnh nư/nam dao động từ $4: 1-8: 1$ tùy theo nghiên cứu và chủng tộc [6]. Độ tuổi trung bình của nhóm trẻ trong nghiên cứu của chúng tôi là 9,75 tuổi. Jaruratanasirikul và cộng sự nghiên cứu trên 46 bệnh nhi bướu cổ có sự xuất hiện của kháng thể kháng tuyến giáp, độ tuổi trung bình là $12,4 \pm 1,7$ tuổi [6]; 11,4 tuổi là tuổi trung bình của 54 trẻ HT trong nghiên cứu của tác giả Kakourou và cộng sự [7]. Như vậy, tuổi trung 
bình của trẻ trong nghiên cứu của chúng tôi nhỏ hơn so với các nghiên cứu trên có thể do bệnh nhân viêm tuyến giáp Hashimoto ở trạng thái cường giáp có biểu hiện triêuu chứng sớm, dễ nhận biết để đi khám sớm hơn nhóm ít triệu chứng ở giai đoạn suy giáp. Trong nghiên cứu của chúng tôi, trẻ nhỏ nhất được chẩn đoán bênh là 3 tuổi. Theo y văn, viêm tuyến giáp Hashimoto ít gặp trẻ dưới 3 tuổi, thường gặp hơn ở trẻ trên 6 tuổi và hay gặp nhất ở trẻ 10 11 tuổi. Bên cạnh các đặc điểm về tuổi và giới, HT bi ảnh hưởng bởi 2 yểu tố là di truyền và môi trường. Các nghiên cứu về gia đình và các cặp sinh đôi chỉ ra bằng chứng về tính nhạy cảm di truyền. Nghiên cứu của Dittmar và cộng sự cho thấy trẻ có bố me hoăc anh chi em ruột bi HT có nguy cơ mắc bệnh cao hơn lần lượt là 32 và 21 lần so với trẻ không có tiền sử gia đình. Nghiên cứu phân tích gen, giải trình tự toàn bộ hệ gen đã xác đinh được 7 gen liên quan đến bềnh lý tuyến giáp tự miễn (HLA-DR, CD40, CTLA-4, PTPN22, Thyroglobulin ( $\mathrm{Tg}$ ) and TSH receptor) [8]. Trong nghiên cứu này, chúng tôi ghi nhận 8 trường hợp tiền sử gia đình có bệnh lý tưyên giáp, hầu hết là cường giáp, một trường hợp có bố và một trường hợp có me bị ung thư tuyến giáp. Điều này có thể do gia đình bệnh nhân chủ yếu đi khám và phát hiện được bẹnh qua các biểu hiện của cường giáp mà bỏ qua những triệu chứng âm thầm của trạng thái suy giáp trong HT. Do đó, sàng lọc bệnh lý tuyến giáp tự miễn và theo dõi định kỳ đối với những thành viên khác trong gia đình, cũng như phân tích di truyền cho trẻ là điều cần thiết.

Bướu cổ là lý do hay gặp nhất khiến bệnh nhân phải đi khám, tiếp đó là gầy sút cân, hồi hộp đánh trống ngực hay mệt mỏi. Những triêuu chứng cường giáp biểu hiện trong viêm tuyển giáp Hashimoto tương tự những triệu chứng có thể gặp do bênh Graves do tác dụng của hormon tuyến giáp lên mô đích. Do đó, chẩn đoán phân biệt nguyên nhân cường giáp do 2 bệnh lý này trển lâm sàng là vô cùng khó khăn. Trong bênh cảnh của 2 bệnh lý trên, hình ảnh mô bệnh học đều cho thấy hiện tượng phản ứng và xâm nhẩp của tế bào lympho $T$ xung quanh các tế bào tuyến giáp. Trong bệnh Graves, tế bào lympho $T$ Helper 2 kích thích sản xuất kháng thể kháng TSH-Receptor bởi tế bào lympho $B$. Trong bệnh viêm tuyến giáp Hashimoto, tế bào lympho $T$ Helper 1 xâm nhập vào tuyến giáp gây nên sự chết theo chu trình của các tế bào nang tuyến giáp, thường gây ra suy giáp [9]. Chẩn đoán xác định và chấn đoán nguyên nhân được thực hiện thông qua xét nghiệm hóa sinh và chẩn đoán hình ảnh.

Các chỉ số hóa sinh cho thây tình trạng cường chức năng tuyến giáp với T3, FT4 tăng và TSH giảm. Nồng độ T3 thường tăng mức độ nhẹ đến trung bình trong nhóm viêm tuyến giáp Hashimoto. Tình trang này có thể kéo dài từ vài tuần đến vài tháng, mức độ nặng của các triêu chứng lâm sàng có liên quan đến nồng độ của Anti TPO trong máu, và nếu có măt của TRẢb thì giai đoann này sẽ có thể kéo dài hớn. Khi tiếp cận bênh nhân bướu cổ, có hay không có kèm theo các triệu chứng của cường giáp, xét nghiệm chức nắng tuyến giáp cùng các kháng thể kháng thể Anti $-\mathrm{Tg}$, Anti - TPO và TRAb là điều không thể bỏ qua. Hai kháng thể Anti - Tg và Anti TPO còn được gọi là kháng thể kháng microsom, trong giai đoạn đầu của HT thì Anti - Tg tăng rõ, Anti - TPO tắng vừa; sau đó Anti - Tg giảm dần và có thể biến mất, nhưng Anti - TPO vẫn tồn tại nhiều năm. Trong nghiên cứu của chúng tôi, kháng thể kháng tuyến giáp với nồng độ trong máu tăng cao, nồng đô Anti - Tg cao nhất trong máu của bênh nhân là $53172 \mathrm{U} / \mathrm{ml}$ và nồng độ cao nhất của Anti - TPO là $2608 \mathrm{U} / \mathrm{ml}$. Nồng độ TRAb trong máu cũng góp phần tiên lương quá trình bệnh, sự có mặt của kháng thể này đồng nghĩa trang thái cường giáp sẽ kéo dài hơn [5]. Xét nghiệm kháng thể kháng tuyến giáp có vai trò quan trong giúp cho việc theo dõi và tiên lượng. De Luca và cộng sự báo cáo xét nghiệm có tăng Anti - Tg và Anti - TPO khi nghiên cứu trên 608 trẻ (Italy), tại thời điểm chẩn đoán có $52,1 \%$ bình giáp, $41,4 \%$ suy giáp và $6,5 \%$ cường giáp. Theo dõi sau 5 năm, $50 \%$ số bệnh nhân có trạng thái bình giáp tiến triển suy giápvà $50 \%$ trẻ suy giáp trở lại trạng thái bình giáp. Kháng thể kháng tuyến giáp tăng ở trẻ càng nhỏ thì nguy cơ tiến triển suy giáp càng cao [9]. Tác giả Wasniewska và cộng sự đã theo dõi 14 trẻ em mắc bệnh tuyến giáp tự miễn, TRAb âm tính và cường giáp xảy ra trong vòng một vài tháng kể từ chẩn đoán ban đầu. Sau khi tình trangcường giáp được điều trị, không có trường hợp tái phát nào được ghi nhận sau 9 năm khi chẩn đoán viêm tuyến giáp tự miễn. Theo các nghiên cứu theo dõi dọc trên các nhóm bệnh nhân cường giáp, tiên lượng khả năng tái phát tình trạng cường giáp trong viêm tuyến giáp Hashimoto thấp hơn nhiều so với bênh Graves. Ngoài ra, trong nhóm nghiên cứu có 1 bệnh nhân đến vì lý do co giật kèm tăng huyết áp $(170 / 110 \mathrm{mmHg})$, bệnh nhân đã được tìm các nguyên nhân gây tăng huyết áp, tuy nhiên 
không phát hiện được nguyên nhân nào khác. Diễn biến lâm sàng dần ổn định khi điều trị tình trạng cường giáp, huyết áp bệnh nhân trở về bình thường khi bệnh nhân đạt trạng thái cường giáp $(110 / 60 \mathrm{mmHg})$. Do đó, khi tiếp cận bệnh nhân tăng huyết áp cần kiểm tra chức nắng tuyến giáp của bệnh nhân.

Điều trị bằng hormon kháng giáp là cần thiết nhằm cân bằng lại chuyển hóa và giúp bệnh nhân trở lại trạng thái bình giáp. Liều điều trị trung bình của bệnh nhân là $0,59 \mathrm{mg} / \mathrm{kg} / \mathrm{ngày}$. Bên cạnh đó, thuốc chẹn thụ thể beta giúp điều hòa nhịp tim, dùng khi mạch của bệnh nhân > 90 lần/phút (mạch khi ngủ). Theo dõi cẩn thận chức năng tuyến giáp, nồng độ kháng thể kháng tuyến giáp trong máu là rất quan trọng để xác định tình trạng cường giáp của bệnh nhân cả về mặt đáp ứng điều trị, giai đoạn suy giáp cũng như tái phát của bệnh.

\section{KẾT LUÂN}

Bướu cổ là triệu chứng hay gặp nhất bên cạnh những biểu hiện cường giáp điển hình đi kèm khiến trẻ đến khám trong bệnh cường giáp do viêm tuyến giáp Hashimoto. Xét nghiệm kháng thể kháng giáp giúp chẩn đoán và tiên lượng bệnh. Xét nghiệm chức năng tuyến giáp để chẩn đoán, theo dõi và điều trị. Phát hiện sớm và điều trị kịp thời nhằm hạn chế ảnh hưởng đến phát triển thể chất, tẩm thần và phòng tránh biến chứng. Điều trị bằng thuốc kháng giáp trạng. Tiếp cận bệnh nhân cường giáp cần tìm nguyên nhân giúp cho quá trình theo dõi, điều trị và tiên lượng bệnh.

VIẾT TẮT. T3: Triidothyronine

FT4: Free Thyoxin
TSH: Hormon kích thích tuyến giáp

Anti - Tg: Anti Thyroglobulin

Anti - TPO: Anti Thyroid Peroxidase

TRAb: TSH receptor antibodies

\section{TÀI LIỆU THAM KHẢO}

1. Caturegli P., De Remigis A., Rose N.R. (2014). Hashimoto thyroiditis: Clinical and diagnostic criteria. Autoimmunity Reviews,13(4), 391-397.

2. Wasniewska M., Vigone M.C., Cappa M. et al. (2007). Acute suppurative thyroiditis in childhood: relative frequency among thyroid inflammatory diseases. J Endocrinol Invest, 30(4), 346-347.

3. Takasu N., Yamada T., Sato A. et al. (1990). Graves' Disease Following Hypothyroidism Due To Hashimoto's Disease: Studies Of Eight Cases. Clinical Endocrinology, 33(6), 687-698.

4. Radetti G., Gottardi E., Bona G. et al. (2006). The natural history of euthyroid Hashimoto's thyroiditis in children. The Journal of Pediatrics, 149(6), 827-832.

5. Wasniewska M., Wasniewska M., Corrias A. et al. (2012). Outcomes of Children with Hashitoxicosis. HRP, 77(1), 36-40.

6. McGrogan A., Seaman H.E., Wright J.W. et al. (2008). The incidence of autoimmune thyroid disease: a systematic review of the literature. Clinical Endocrinology, 69(5), 687-696.

7. Jaruratanasirikul ' $S_{\text {., }}$ 'Leethanaporn $K_{\text {., }}$ Khuntigij P. et al. (2011). The Clinical Course of Hashimoto's Thyroiditis in Children and Adolescents: 6 Years Longitudinal Follow-up. Journal of Pediatric Endocrinology and Metabolism, 14(2), 177-184.

8. Dittmar M., Libich C., Brenzel T. et al. (2011). Increased familial clustering of autoimmune thyroid diseases. Horm Metab Res, 43(3), 200-204.

9. Marazuela M., García-López M.A., FigueroaVega N. et al. (2006). Regulatory $T$ Cells in Human Autoimmune Thyroid Disease. J Clin Endocrinol Metab, 91(9), 3639-3646.

\section{ĐẶC ĐIỂM LÂM SÀNG, CÂ̂N LÂM SÀNG NGộ ĐộC CẤP METHANOL}

\section{TÓM TẮT}

Mục tiêu: Nhận xét đặc điểm lâm sàng, cận lâm sàng ngộ độc cấp methanol. Đối tượng và phương pháp: Nghiền cứu mô tả trên 107 bệnh nhân ngộ độc cấp methanol điều trị tại Trung tâm chống độc bệnh

*Trung Tâm Chống Độc - Bệnh viện Bạch Mai Chịu trách nhiệm chính: Đặng Thị Xuân Email: xuandangthi17@gmail.com Ngày nhận bài: 25.12.2020

Ngày phản biên khoa học: 11.2.2021

Ngày duyệt bài: 23.2.2021
Đặng Thị Xuân*

viện Bạch Mai từ 01/2016 đến 07/2019. Kết quả: Bểnh nhân nam $(97,2 \%)$; tuổi trung bình là 47,6 \pm 12,6 ; tỉ lệ tử vong cao $(41,1 \%)$. Đặc điểm lâm sàng: đau đầu và nhìn mờ gặp nhiêuu nhất $(94,4 \%)$, hôn mê sâu $(63,6 \%)$, giãn đồng tử $(61,7 \%)$, mất phản xạ ánh sáng $(45,8 \%)$, suy hô hấp $(79,4 \%)$, suy thân cấp $(54,2 \%)$, tụt huyết áp $(31,8 \%)$, co giật gặp ít nhất $(6,5 \%)$. Nhóm BN tử vong gặp ở tỉ lệ cao hơn nhóm sống. Đặc điểm cận lâm sàng: toan chuyển hóa nặng, ALTT, KT ALTT, KT anion, CK, lactat, đường máu đều cao, các chỉ số của nhóm tử vong cao hơn nhóm sống $(p<0,05-p<0,01)$. Nồng độ methanol máu cao $157,1 \pm 90,06 \mathrm{mg} / \mathrm{dL}$, nhóm tử vong cao hơn nhóm 